\title{
学生“浅层” 参与课堂学习反思
}

\author{
贾秉权 ${ }^{1,2}$ \\ 1 西北师范大学, 甘肃 兰州 730070 \\ 2 武警警官学院, 四川 成都 610213
}

\begin{abstract}
[摘要]《深化新时代教育评价改革总体方案》中强调了学生课堂参与及考核的灵活性, 突出了向以 “高阶思维” 为特征的课 堂学习的回归，这也是当今发达国家教育改革的主要趋势，然而目前学生 “浅层” 参与课堂学习问题突出，表现为知识与事 物的分离, 知识与行动的分离, 知识与意义的分离, 文中基于 “高阶思维能力” 视角, 具体从复杂的知识加工, 有意义的知 识建构, 解决问题的知识应用, 批判性四个视角对学生 “浅层” 参与课堂学习进行反思, 接着从强调主体自主的参与行为, 强化知识迁移的参与内容, 确立促进人全面发展的参与目标三个方面提出了对策。
\end{abstract}

[关键词]高阶思维; 浅层参与; 课堂学习; 评价

DOI：10.33142/fme.v2i1.3939 中图分类号：G420 文献标识码：A

\section{Reflection on Students' "Shallow" Participation in Classroom Learning}

\author{
JIA Bingquan ${ }^{1,2}$ \\ 1 Northwest Normal University, Lanzhou, Gansu, 730070, China \\ 2 Officers College of PAP, Chengdu, Sichuan, 610213, China
}

\begin{abstract}
The overall plan for deepening the reform of education evaluation in the new era" emphasizes the flexibility of students' classroom participation and assessment and highlights the return to classroom learning characterized by "high-level thinking", which is also the main trend of education reform in developed countries. However, at present, the problem of students' "shallow" participation in classroom learning is prominent, which is manifested in the separation of knowledge and things. Based on the perspective of "higher-order thinking ability", this paper reflects on students' "shallow" participation in classroom learning from four perspectives: complex knowledge processing, meaningful knowledge construction, problem-solving knowledge application and critical learning. Then, it emphasizes the participation behavior of subject autonomy and strengthens the participation content of knowledge transfer. Finally, it puts forward the countermeasures from three aspects.
\end{abstract}

Keywords: higher order thinking; shallow participation; classroom learning; evaluate

\section{引言}

2020 年 10 月 13 日，中共中央、国务院印发了《深化新时代教育评价改革总体方案》 ${ }^{1}$, 要求: “完善过程性考核与 结果性考核有机结合的学业考评制度, 加强课堂 “参与” 和课堂纪律考查, 引导学生树立良好学风”, 强调了新时代教育 评价中要重视学生课堂参与, 强调考核的灵活开放性, 都指向了对学生 “深度学习” 的要求, 强调学生的 “深度学习” 也 是落实立德树人根本任务的要求。当下教育因为极度追求工具理性, 沉迷于客观量化, 导致教育生态问题突出, 高阶思 维能力被追求 “短平快” 的评价所遮蔽, 本文立足高阶思维的视角, 对当下学生 “浅层” 参与课堂学习的现状加以省思。

\section{1 相关概念界定}

\section{1 “浅层”参与课堂}

一般依据布鲁姆的认知目标分类学, 学生在课堂上没有应用、分析、评价、创造的思维活动发生, 只有记忆和简 单理解被认定为 “浅层” 参与课堂 ${ }^{2}$ 。

本文对 “浅层” 参与课堂界定为: 就是学生在课堂学习中, 没有全身心积极参与、学生没有掌握学科的核心知识, 没有理解学习的过程, 没有把握学科的本质及思想方法, 内在学习动机不高、态度不积极, 缺乏独立性、批判性、创造性。

\section{2 高阶思维}

即在 “深度学习” 中所运用的核心思维, 1976 年, 马顿和塞利奥最早提出 “深度学习” 概念, 认为深度学习是在 理解基础上, 学习者能够批判地学习新思想和事实, 把他们融入原有的认知结构中, 并能够将已有的知识迁移到新的 情境中, 做出决策, 并进行解决问题, ${ }^{3}$ 即为, 深度学习所需要的批判理解、内容整合、知识建构与迁移运用的思维就 
是高阶思维。

\section{2 学生 “浅层” 参与课堂表现}

\section{1 顺从参与一一知识与事物的分离}

在顺从式参与中, 知识与事物的分离中, 学生直接与知识的外壳和形式发生关系, 获得了大量缺乏实际内容的且枯 燥乏味的空洞知识。学生所学的知识远离生活, 脱离实际, 记忆知识就是为了分数, 背诵古诗体会不到诗人深层次的 情感, 只要在考试中能写出来就认为达到了目的, 没有当作一种陶冶; 学几何目的是作对题, 学习了若干年几何, 生 活中固定物体时都想不到运用 “三角形具有稳定性” 的原理; 历史学习了好多年, 不能从历史荣辱得失, 是非成败中 启发当下, 学历史就是为了记住知识来应对考试。因而, 学生在学习参与过程中很少有对所学知识深层次的理解, 毫 无质疑的完全接受了教师和教材观点。学生在课堂学习中的顺从式参与体现了学生因屈服于外部评价而被动采取的一 种行为。教师是 “社会代表者” 的制度权威, 学生出于对教师的敬畏不敢对其质疑。教师又是传道授业解惑的知识权 威, 学生学习的内容是科学化的, 是业内专家编修的, 考试内容出自于其中, 可视为考试正确答案的代名词, 学生不 敢质疑也不会质疑, 如果有些同学质疑知识却没有在考试中取得高分, 必为他人所耻笑。长此以往, 学生在课堂上习 惯了对知识的盲信, 自主学习能力不能得到提高。

\section{2 隐形逃课一一知识与行动的分离}

“隐形逃课” 的学生是身体在场而理智思维缺席, 知识和行动发生了分离, 表现是 “开小差”, 学生胡思乱想, 眼 神涣散, 表情或笑或恼或呆滞, 注意力难集中。老师讲的口干舌燥, 学生听的无动于衷, 老师讲的精彩还是乏味, 与 学生无关, 老师一提问, 学生非常自然的回答 “我不会” 三个字, 依然我行我素, “专心” 的干自己的事情, 真是 “躲 进小楼成一统, 管它春夏与秋冬”, 具体表现为有看其他科目的, 练字的, 写作业的, 看小说的, 刷朋友圈的, 聊微信 的, 看空间的, 玩游戏的, 上网的, 还有睡觉, 小声聊天的, 甚至有吃零食补妆小声打电话的, 老师在做没有观众的 表演, 学生 “人在曹营心在汉”, 实际上并没有将自己作为学习的主体参与到课堂学习中, 抱着一种随心所遇干自己的 事情的心态。即使偶尔从其他状态回到了课堂, 因为前边没听, 后边也跟不上, 学习质量难以保证, 高阶思维能力就 更不的不到激发。另一种知识与行动分离的表现是, 在课堂教学中, 学生会对学校规章制度和课堂集体规范产生服从, 学生来到了课堂, 甚至有些人也会参与教师互动, 参与班级的讨论和分享, 但是并没有积极参与学习活动, 因为都非 发自内心的渴望和理性思考后的主动回答, 最多是一种对权威的配合, 使学习停留在知识输入输出表层, 没有深入参 与到课堂学习, 习惯于既不积极参与也不明确抵抗的消极罢工。

\section{3 被动学习——知识与意义的分离}

知识与意义的分离在课堂的表现为被动学习, 一是 “无可奈何花落去” 的感觉, 个人无能为力改变环境, 对自己 要做的事情力不从心。二是 “无意义感”, 即个体对自己的生活和所从事的工作感受不到意义, “任尔东西南北风” 我 自崩然不动, 缺乏动力。无能力的参与是指学生基础差, 理解有障碍, 对教师所授知识消化不了, 首尾不能兼顾, 跟 不上老师的上课节奏, 不能有效控制自己学习的行为, 由于能力不足而无法深度参与, 思维一直在低层次俳徊。学生 对学习活动感受不到价值和意义, 内心不认同, 对于课堂学习按部就班的进行表现出缺乏主动性, 感觉有心无力, 甚 至是无意义, 形式上听一下就好了。教育不仅要批判性的传承知识, 还要通过知识的学习建构自身的意义, 学生没有 深层次学习, 没有高阶思维能力的激发。

\section{3 对学生 “浅层” 参与课堂反思}

“高阶思维”能力的特征分为复杂的知识加工, 有意义的知识建构, 解决问题的知识应用, 批判性, 活动与体验, 本文依据其特征对学生 “浅层”参与课堂学习进行评价。

\section{1 复杂的知识加工视角}

高阶思维能力是《评价改革总体方案》所强调的核心培养能力, 学生浅层次的课堂参与仅仅是对知识的识记和表 象理解, 缺乏对知识的应用、评价和创新, 不能形成各层次之间自循环式的内在相互促进和巩固关系, 达不到万圣师 表孔子提出了 “不愤不启, 不悱不发, 举一隅不以三隅反, 则不复也” 的学习要求, 最终不能达成对知识的深度理解 与运用, 高阶思维能力得不到激发和培养。

\section{2 有意义的知识建构的视角}

奥苏贝尔认为有意义学习指符号所代表的新知识与学习者认知结构中已有的适当概念建立非人为的、实质性联系 
的过程。 ${ }^{4}$ 知识是和其他的知识之间存在着联系, 因此在学习中, 重要的是将新知识与已有的知识进行整合, 以结构化 的方式掌握知识。浅层参与学习浅尝轩止, 远离生活, 看重结论, 缺乏体验式学习, 不会形成新知识与学生认知结构 中已有知识非人为实质性的联系，只有人为的记诵和机械被动的练习，高级思维能力得不到完善。

\section{3 解决问题的知识应用视角}

高阶思维的认知目标, 本质在于对知识进行迁移。通过加深对知识的理解和迁移达成问题的解决与创新, 高阶思 维能力的培养必须以解决实践中的问题为宗旨。浅层次课堂学习表现为参与顺从、被动、隐形逃课, 为纪律而上课, 为分数而识记, 为权威而互动, 不为生活, 也没有知识的迁移, 更不可能有创新, 培养成了陶行知所言的 “种地不如 老子, 喂鸡不如嫂子” 的眼高手低的人, 高阶思维更不会出现。

\section{4 批判性视角}

在高阶思维研究的文献中, 不少学者都频繁地使用 “批判性” 这个术语去代表其他所有类型的高阶思维。学生学 习的终极目的在于通过对所学知识的批判形成学生自觉且理性的精神和正确的价值观。浅层次学习顺从权威, 感到学 习无意义, 或者感觉学不懂无能为力, 甚至隐形逃课, 人在心不在, 不可能有批判能力的形成。

\section{4 学生课堂 “浅层”参与表现的对策}

\section{1 强调主体自主自觉的参与行为}

知之者不如好之者, 好之者不如乐之者。前苏联著名教育家苏霍姆林斯基在《教育与自我教育》一书中提出 “真 正的教育是自我教育”, 他明确指出 “教育在广义上就是对集体的教育和对个人的教育的统一; 而在对个人的教育中, 自 我教育是起主导作用的方法之一。” ${ }^{5}$ 强调了真正的学习是知识经过了高阶思维内化后视如已出。学生课堂参与从表层 走向深层要求主体积极主动的深度参与行为、强化迁移的参与内容、确立人的全面发展的参与目的。“教育的根本使命 就是促使每个主体的生成。人的自主性、自主意识需要在教育和实践中生成。教育的作用在使人意识到作为一个自主 体的地位和责任。” ${ }^{6}$ 强烈的动机是学生本人对于学习本身价值的认同, 要求学生具有主动参与的意识同时掌握学习的 方法。

\section{2 强化知识内化与迁移的参与内容}

强调标准答案的学习是窄化了学习的乐趣, 学生学习应该强调内化与迁移。学习中要加强联想, 追求迁移默化的 学习。正如波兰尼所言, “评判学生掌握知识的标准在于能否将显性知识转化为默会知识。” ${ }^{7}$ 学生对知识的体验和内化 理解, 让学生在生活世界中感知知识的用途, 来达到对知识意义的深层次理解, 知识只有回归到生活才有意义。其二, 知识的迁移和运用。怀特海指出, “教育使人获得运用知识的技能。” 学生在课堂学习中学习思维比学习知识更重要, 能够把在相似的情境中运用知识解决实际问题, 这样才会感觉到学习的有用性。

\section{3 确立促进人发展与完善的参与目标}

“人类整个生活和历史发展的终极目的是人自身的完善，而教育在实现人类的终极目的中作用至关重要，教育的 基本使命就是要使人形成智慧。” ${ }^{8}$ 学习深度参与具有促进学生全面发展、提升教育教学质量的重要意义。由于人是在 教育的引导下, 通过在主体间和主客体间的相互作用中所实现的经验改造和意义建构, 因而, 走向高阶思维的学习才 可以真正完善人的发展, 使课堂学习成为自我发展和完善的实践活动。

\section{[参考文献]}

[1]余文森著.个体知识与公共知识课程变革的知识基础研究 [M]. 北京: 教育科学出版社,2010.

[2]Eric Jensen,Le Ann Nicke1sen. 深度学习的 7 种有力策略 [M]. 温暖译. 上海: 华东师范大学出版社,2009.

[3]Ausube1, D. P. \& Robinson, F. School Learning: An Introduction to Educational Psychology[M]. New York: Holt, Rinehart and Winston, 1969.

[4] 苏霍姆林斯基. 给教师的一百条建议 [M]. 天津: 人民出版社, 1981.

$[5]$ 鲁洁. 教育的原点: 育人 $[\mathrm{J}]$. 华东师范大学学报(教育科学版), 2008 (4) : 10 .

[6]罗祖兵,郭超华.知识学习的体验属性及其教学意蕴 $[\mathrm{J}]$. 教育研究, 2019(11) : 11 .

$[7]$ 王鉴. 论教育与生活世界的关系 $[\mathrm{J}]$. 华中师范大学学报 (人文社会科学版), 2006 (3) : 12 .

作者简介: 贾秉权 (1986.4-), 西北师范大学教育学院博士研究生, 武警警官学院讲师, 主要研究方向为教育理论。 